\title{
SPECTROSCOPIC DIAGNOSTICS OF TRITIUM RECYCLING IN TFTR
}

\author{
BY \\ C.H. Skinner, D.P. Stotler, H. Adler, A.T. Ramsey, et al. \\ Presented at the Tenth Topical Conference on \\ High Temperature Plasma Diagnostic Conference \\ Rochester, NY, 8-12 May, 1994
}

\section{DISCLAIMER}

This report was prepared as an account of work sponsored by an agency of the United States Government. Neither the United States Government nor any agency thereof, nor any of their employees, makes any warranty, express or implied, or assumes any legal liability or responsibility for the accuracy, completeness, or usefulness of any information, apparatus, product, or process disclosed, or represents that its use would not infringe privately owned rights. Reference herein to any specific commercial product, process, or service by trade name, trademark, manufacturer, or otherwise does not necessarily constitute or imply its endorsement, recommendation, or favoring by the United States Government or any agency thereof. The views and opinions of authors expressed herein do not necessarily state or reflect those of the United States Government or any agency thereof.

\section{Work supported by U.S. Department of Energy Contract DE-AC02-76CHO-3073}

\section{Princeton University Plasma Physics Laboratory}




\section{DISCLAIMER}

Portions of this document may be illegible in electronic image products. Images are produced from the best available original document. 


\title{
Spectroscopic Diagnostics of Tritium Recycling in TFTR.
}

\author{
C H Skinner, D P Stotler, H Adler, A T Ramsey, \\ Princeton University, Plasma Physics Laboratory, \\ PO Box 451. Princeton N J 08543.
}

We present the first spectroscopic measurements of tritium Balmeralpha $\left(T_{\alpha}\right)$ emission from a fusion plasma. A Fabry-Perot interferometer is used to measure the $H_{\alpha}, D_{\alpha}, T_{\alpha}$ spectrum in the current $D-T$ experimental campaign on TFTR and the contributions of $\mathrm{H}, \mathrm{D}$ and $\mathrm{T}$ are separated by spectral analysis. The $T_{\alpha}$ line was measurable at concentrations $T_{\alpha} /\left(H_{\alpha}+D_{\alpha}+T_{\alpha}\right)$ down to $2 \%$.

\section{INTRODUCTION}

D-T plasmas in TFTR ${ }^{1}$ are typically fueled by neutral beams but hydrogenic ions, recycled from the limiter, are a major factor in plasma composition and reactivity. The recycling can be observed in Balmer-alpha emission from neutral hydrogen isotopes at the plasma edge. ${ }^{2}$ The atomic velocities, arising from dissociation and charge exchange, are mapped in the Doppler broadened line profiles. The tritium Balmer-alpha $\left(T_{\alpha}\right)$ emission wavelength is slightly shifted from that of deuterium Balmer-alpha $\left(D_{\alpha}\right)$ by the small difference in the reduced mass of the nucleus/electron system and is at $6560.45 \AA$ compared to $6561.04 \AA$ for deuterium. This wavelength difference is a factor three smaller than the separation between $\mathrm{H}_{\alpha}$ and $D_{\alpha}$ and is comparable to the Doppler width of the lines. The relative amount 
of tritium-alpha. $T_{\alpha} /\left(\mathrm{H}_{\alpha}+\mathrm{D}_{\alpha}+\mathrm{T}_{\alpha}\right)$, is low even in plasmas with $100 \%$ tritium neutral beam injection because the recycled tritium influx is highly diluted by the pre-existing inventory of deuterium in the limiter. The experimental challenge is then to detect a small level of $T_{\alpha}$ that is blended into the $D_{\alpha}$ emission line. We report observations of the $H_{\alpha}, D_{\alpha}, T_{\alpha}$ spectra with a Fabry-Perot interferometer in which $T_{\alpha}$ emission at levels down to $2 \%$ of the total $\left(H_{\alpha}+D_{\alpha}+T_{\alpha}\right)$ was successfully detected.

\section{EXPERIMENTAL SETUP}

The experiment was conceived at the time TFTR was intensively involved with preparations for $D-T$ operation and installation of new equipment on the machine was highly circumscribed. Fortunately an array of telescopes coupled by fiberoptics to a remote system of interference filters and detectors (dubbed HAIFA ${ }^{3}$ ), was in place to monitor the combined $\mathrm{H}_{\alpha}, \mathrm{D}_{\alpha}$ emission and it was possible to use a spare channel in this system to bring light from the plasma to a data acquisition room situated 50M distant from the TFTR. Balmer-alpha emission occurs at the inner graphite limiter where the magnetic field of 7 Tesla causes the line to be split into two $\sigma$ components displaced by $\pm 1.4 \AA$ polarized perpendicular to the field, and an undisplaced $\pi$ component polarized parallel to the field. A sheet Polaroid polarizer was attached to the front of a telescope and oriented to transmit only the undisplaced $\pi$ component.

The set up is shown in Fig. 1. Light from TFTR was collected by a telescope and transmitted via a $1 \mathrm{~mm}$ diameter fiber optic to the data acquisition room. On exiting the fiber, the light from the plasma was recollimated. filtered with a $10 \AA$ bandpass filter and re injected to a second fiber. The maximum transmission wavelength of the filter was set to the $D_{\alpha}$ wavelength by a slight rotation of the 
filter. In this procedure a tungsten lamp and scanning monochromator were used to provide tunable light source and the filter transmission monitored on a chart recorder. A hydrogen discharge lamp was used for wavelength calibration of the monochromator.

A Fabry-Perot (Burleigh TL38) was used to spectrally resolve the $H_{\alpha}, D_{\alpha}, T_{\alpha}$ emission. The free spectral range of the Fabry-Perot was set to $7 \AA$ to encompass the complete $H_{\alpha}, D_{\alpha}$ and $T_{\alpha}$ line spectrum. The finesse available from the existing mirror set was 30 giving a resolution of $0.23 \AA$. Such a resolution is also potentially available from a large monochromator, however the Fabry-Perot has a major advantage in optical efficiency, being a fast. $f 3$ system that can accept light from a $1 \mathrm{~mm}$ optical fiber (no entrance slit is needed) and the resulting high signal/noise ratio is a key factor in detecting tritium at low concentrations. The Fabry-Perot itself is compact (60 $\mathrm{mm}$ diameter and $60 \mathrm{~mm}$ long), and has a fixed invar spacer between the mirrors. Coarse alignment is performed mechanically and three piezoelectric elements are used for fine alignment and temporal scanning. The Fabry-Perot was set to scan over two orders every $200 \mathrm{msec}$ (the lower limit is $20 \mathrm{msec}$ scan time/order) and the transmitted light conveyed via a fiber optic to an RCA R928 photomultiplier. Time variations in the overall $H_{\alpha}, D_{\alpha}, T_{\alpha}$ intensity in the plasma also modulate the Fabry-Perot signal. A beam splitter before the FabryPerot intercepted a small fraction of the light and reflected it back to a separate fiber that transmitted it to a second interference filter set to the $D_{\alpha}$ wavelength and a second photomultiplier. In this way the total $H_{\alpha}, D_{\alpha}, T_{\alpha}$ intensity from exactly the same collection volume was recorded and used to normalize the Fabry-Perot signal and obtain the spectral line profile. Two additional channels were used to monitor the piezo element driving voltages. The four signals were digitized at $2 \mathrm{kHz}$ and archived for subsequent analysis. 
To maintain high resolution it is necessary that any drift in the separation of the Fabry-Perot mirrors be less than $50 \AA$. The instrument was housed in a chamber in which the temperature was maintained at $30^{\circ} \pm 1^{\circ}$. However this, by itself, was not sufficient to maintain alignment for more than 5-10 hours. Since access to the data acquisition room was not possible during machine operations an automated system was implemented to maintain optimal alignment. A helium neon laser beam was used to provide a continuous optical reference signal. The beam was attenuated and input via a fiber optic to the exit telescope in the filter assembly. Some scattered laser light was transmitted along the signal fiber optic to the Fabry-Perot. This appeared in the scanned Fabry-Perot spectrum at a different order to the $H_{\alpha} D_{\alpha} T_{\alpha}$ signal. In a period of 0-7 seconds during a plasma discharge the laser beam was blocked. At other times the measured spectral profile of the laser light provided a continuous monitor of the instrumental resolution. The signal was used in an electronic controller (Burleigh DAS 10) to maintain FabryPerot alignment. The integrated signal in a $10 \mathrm{msec}$ time window (encompassing the whole laser line) was continually optimized by adjusting all three piezo element voltages in a feedback loop with a response of a few seconds. This maintained a constant mirror separation. The integrated signal in a smaller $2 \mathrm{msec}$ time window at the line center was used in a slower feedback loop that simultaneously monitored trial variations in each piezo element in turn to maximize the line center signal and thus maintain optimal alignment. During the six seconds of the plasma discharge the laser and optimization process was automatically turned off. This system was able to maintain optimal Fabry-Perot alignment indefinitely.

\section{INITLAL RESULTS IN DEUTERIUM PLASMAS}

The Fabry-Perot system was first used with discharges fueled by deuterium neutral beam injection (NBI) plus deuterium and a small amount of hydrogen recycled 
from the wall. Of particular interest in the observed $\mathrm{H}_{\alpha} \mathrm{D}_{\alpha}$ line profile was the extent and reproducibility of the line wing of the $D_{\alpha}$ profile at the $T_{\alpha}$ wavelength.

Before tritium operation a 'preview' of the expected $H_{\alpha} D_{\alpha} T_{\alpha}$ spectrum was obtained by adding a simulated $T_{\alpha}$ line profile to the observed $H_{\alpha} D_{\alpha}$ line profile. An approximation to the $T_{\alpha}$ profile was constructed by manipulating the data elements of the short wavelength side of the observed $D_{\alpha}$ profile in a spreadshieet program to generate a complete profile that was shifted to the $T_{\alpha}$ wavelength and narrowed by a factor $v^{\prime}(3 / 2)$ due to the mass difference. Fig. 2 shows the result of adding this to an experimental $\mathrm{H}_{\alpha} \mathrm{D}_{\alpha}$ profile (taken with a $0.6 \mathrm{~mm}$ dia. fiber). At concentrations above $20 \%$ a clear separate peak emerges, below that level, the $T_{\alpha}$ line is apparent in a displacement or 'bulge' in the side of the $D_{\alpha}$ profile. To estimate the level at which $T_{\alpha}$ would be detectable a line fitting program was used. This fit the complete $\mathrm{H}_{\alpha} \mathrm{D}_{\alpha} \mathrm{T}_{\alpha}$ profile to 6 Gaussians, two Gaussians to each isotope, with some constraints from the known relation between the individual line shapes. From analysis of the Gaussians fits an estimate of the $T_{\alpha}$ concentration could be made and compared to the known fraction of simulated $T_{\alpha}$ added to the experimental $\mathrm{H}_{\alpha} \mathrm{D}_{\alpha}$ line. The results ${ }^{4}$ were very promising, and showed good agreement between the input concentration and that estimated from the line fits.

The signal level was increased by increasing the fiber diameter from $0.6 \mathrm{~mm} 0.1 \mathrm{~mm}$ and using a faster lens. An additional factor in the sensitivity of this technique is the reproducibility of the $\mathrm{D}_{\alpha} \mathrm{H}_{\alpha}$ line profile. In the D-T campaign on TFTR significant effort was devoted to producing reproducible discharges so that the effects of tritium on the plasma parameters could be most clearly identified. This resulted in highly reproducible line profiles as can be seen in Fig. 3 which shows a comparison of two $\mathrm{H}_{\alpha} \mathrm{D}_{\alpha}$ profiles from different discharges. The difference in the line profiles, integrated over the area of the $T_{\alpha}$ line. was remarkably low $(0.02 \%)$. 


\section{RESULTS IN DEUTERIUM PLASMAS.}

The first indication of $T_{\alpha}$ became apparent at the end of the first high power campaign (DT7) in discharge \#73273. which used 100\% tritium NBI. The preceding discharge \#73272 was 100\% deuterium NBI, and was used as a comparison discharge. When the line profiles from $\# 73272$ and \#73273 were overlaid, a small but clear difference was apparent at the $T_{\alpha}$ wavelength, similar to a spectrum previously simulated with $2 \%$ tritium concentration. A more quantitative analysis using the line fitting program showed a $2 \%$ increase in the intensity of the profile at the $D_{\alpha}$ wavelength. The clearest evidence for $T_{\alpha}$ emission was obtained by numerically subtracting the line profile for the deuterium discharge from the tritium discharge, revealing a spectral line at the $T_{\alpha}$ wavelength with an area $2 \%$ of the total. In subsequent discharges in second high power D-T campaign (DT9) the level of $\mathrm{T}_{\alpha}$ increased up to several percent. Interestingly, the maximum level of $T_{\alpha} /\left(H_{\alpha}+D_{\alpha}+T_{\alpha}\right)$ of $7.5 \%$ was in a deuterium NBI discharge immediately following tritium NBI: \#74353 shown in Fig. 4. This discharge also exhibited anomalous MHD and sawteeth. Over the following remaining seven deuterium NBI discharges of the day, the $T_{\alpha}$ level decreased relatively slowly with a decay constant of 7.5 discharges.

An overlay of a $T_{\alpha}$ line profile calculated by the Monte-Carlo neutral transport code DEGAS is shown for comparison. When, through dissociation, excitation or charge exchange, a test particle emits an $\mathrm{H}_{\alpha}$ photon in a volume corresponding to the observation volume, the particle velocity is logged and, over thousands of flights, a spectral line profile built up [5]. In the present comparison, the DEGAS profile used plasma parameters from an earlier supershot discharge (\#72422), and the predicted profile was convoluted with the experimental instrument function. This first comparison shows overall harmony between the observed and predicted 
profiles. A more extensive account of the experimental results is given in reference [6]. The D-T experiments will provide a unique opportunity to study tritium edge physics. Further comparisons of the observed and predicted $\mathrm{T}_{\alpha}$ line profiles are planned and will be reported in a subsequent paper.

\section{ACKNOWLEDGMENTS}

We would like to acknowledge the support of the TFTR team, especially the contributions of M. Bell, R V Budny, M. Caorlin, D. Johnson, L C Johnson, D. Mikkelsen and J. Strachan. The technical assistance of J. Bartolick, D. Cylinder, M. Diesso. G. Drodz, and P. Sichta is highly appreciated. This work was supported by the US. Department of Energy Contract No. DE-AC02-76-CH0307

\section{REFERENCES:}

[1] R J Hawryluk H Adler, P Alling et al. Princeton University, Plasma Physics Laboratory Report \# PPPL 2977 (February 1994) 12pp, Phys Rev. Lett. in press: and J D Strachan H Adler. P Alling et al Plasma Physics Laboratory Report \# PPPL 2978 (February 1994) 14pp. Phys Rev. Lett. in press.

[2] D H McNeil, J. Nucl Mater. 162 (1989) 476.

[3] A T Ramsey and S L Tumer, Rev. Sci. Instrum. 58, 1211 (1987).

[4] C H Skinner, A T Ramsey, D W Johnson and M Diesso; PPPL Report PPPL-2878. Feb. 1993.

[5] D P Stotler, C H Skinner, R V Budny, H Adler, and A T Ramsey, presented at the 1994 International fusion Theory Conference. Dallas, March 14-16. 1994 (Univ of Texas. Austin 1994) paper 2C-15.

[6] C H Skinner, H Adler, R V Budny, J Kamperschroer, L C Johnson, A T Ramsey, and D P Stotler; Plasma Physics Laboratory Report \# PPPL 2993 (May 1994) 19pp. 


\section{Figure Captions}

Fig. 1. Experimental Setup

Fig. 2. The lowest trace is the $H_{\alpha} . D_{\alpha}$ spectrum observed in TFTR before tritium operations (discharge $\# 69019$ ). The upper traces simulate the addition of $6 \%$ and $24 \% \mathrm{~T}_{\alpha}$ respectively.

Fig. 3. An overlay of line profiles from two deuterium discharges (\#73443 and \#73441) illustrating the excellent reproducibility of the $\mathrm{D}_{\alpha} \mathrm{H}_{\alpha}$ line profile. The difference, magnified by iour, is plotted in the lower trace. The vertical dashed line marks the wavelength of $T_{\alpha}$ at rest.

Fig. 4. Upper traces shows a comparison of the normalized line profiles from discharge $\# 73448$ in bold and an earlier deuterium comparison discharge before tritium NBI (\#73443; thin trace). The displacement on the short wavelength side of the profile is due to $T_{\alpha}$. The lower traces shows the difference between these profiles magnified by a factor four (scale on the right hand side), and (dotted) a $T_{\alpha}$ profile predicted by DEGAS. The difference profile was smoothed with a filter function to remove noise features beyond the instrumental spectral resolution. 


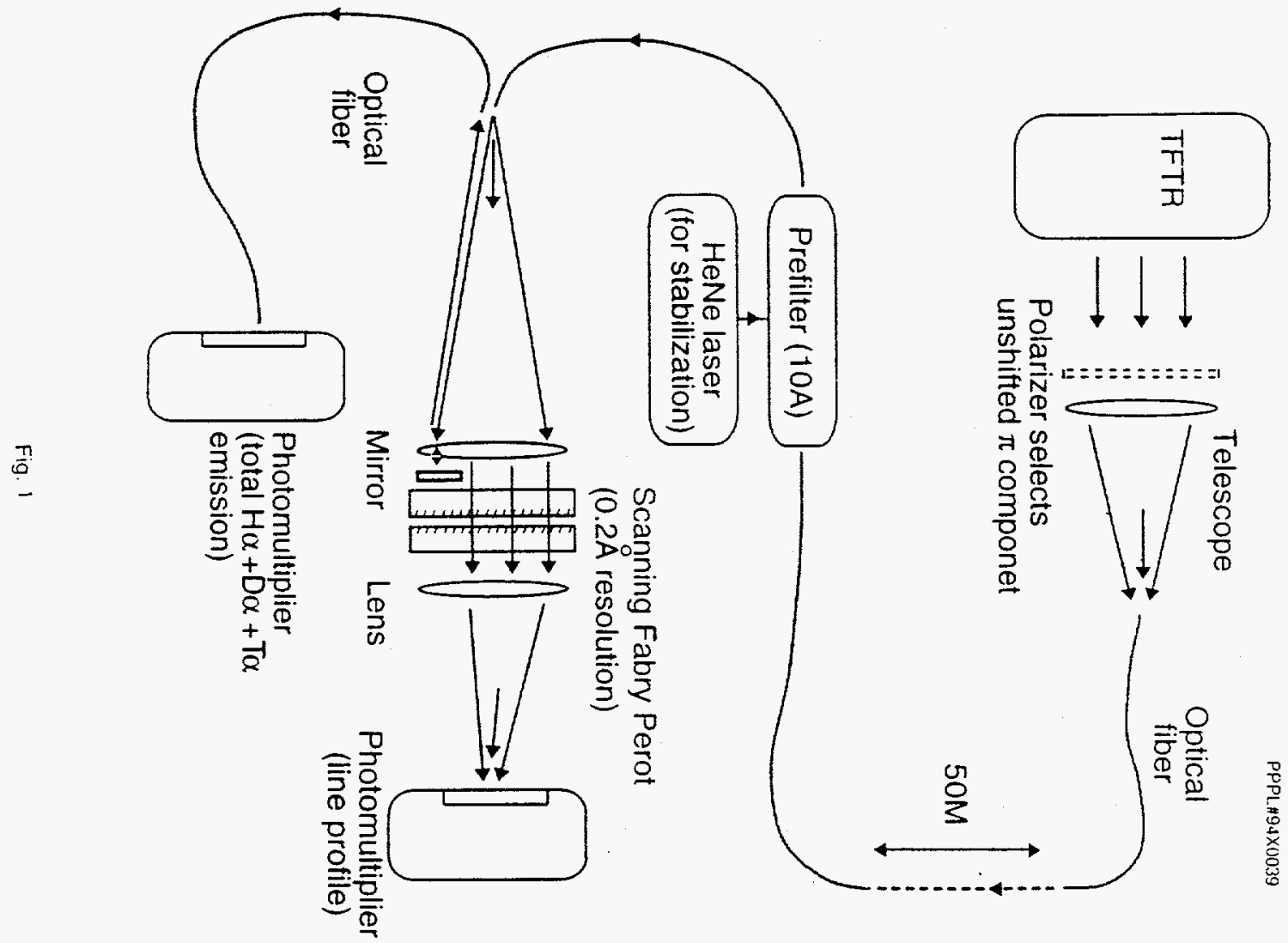

PPPL1194X0040

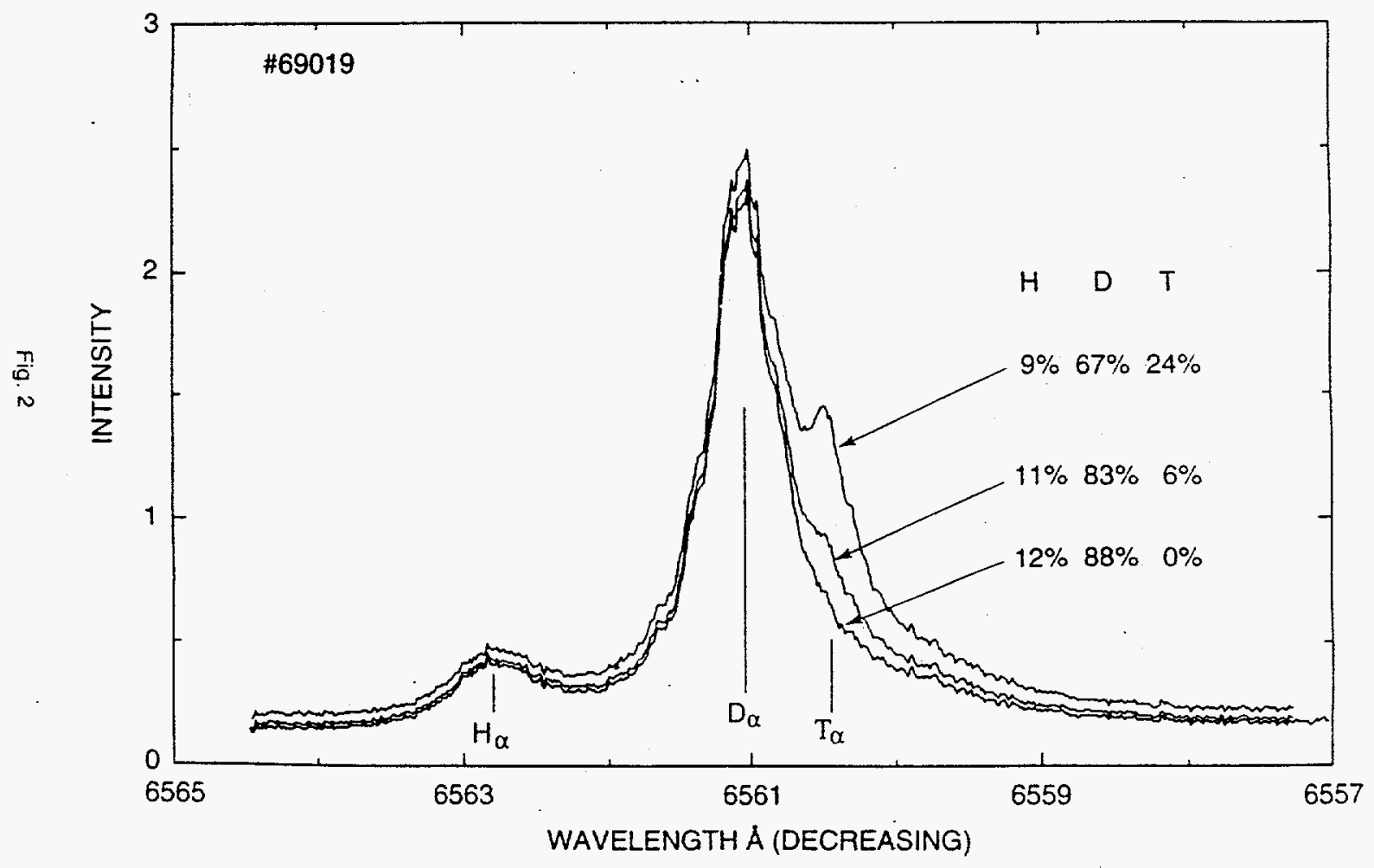




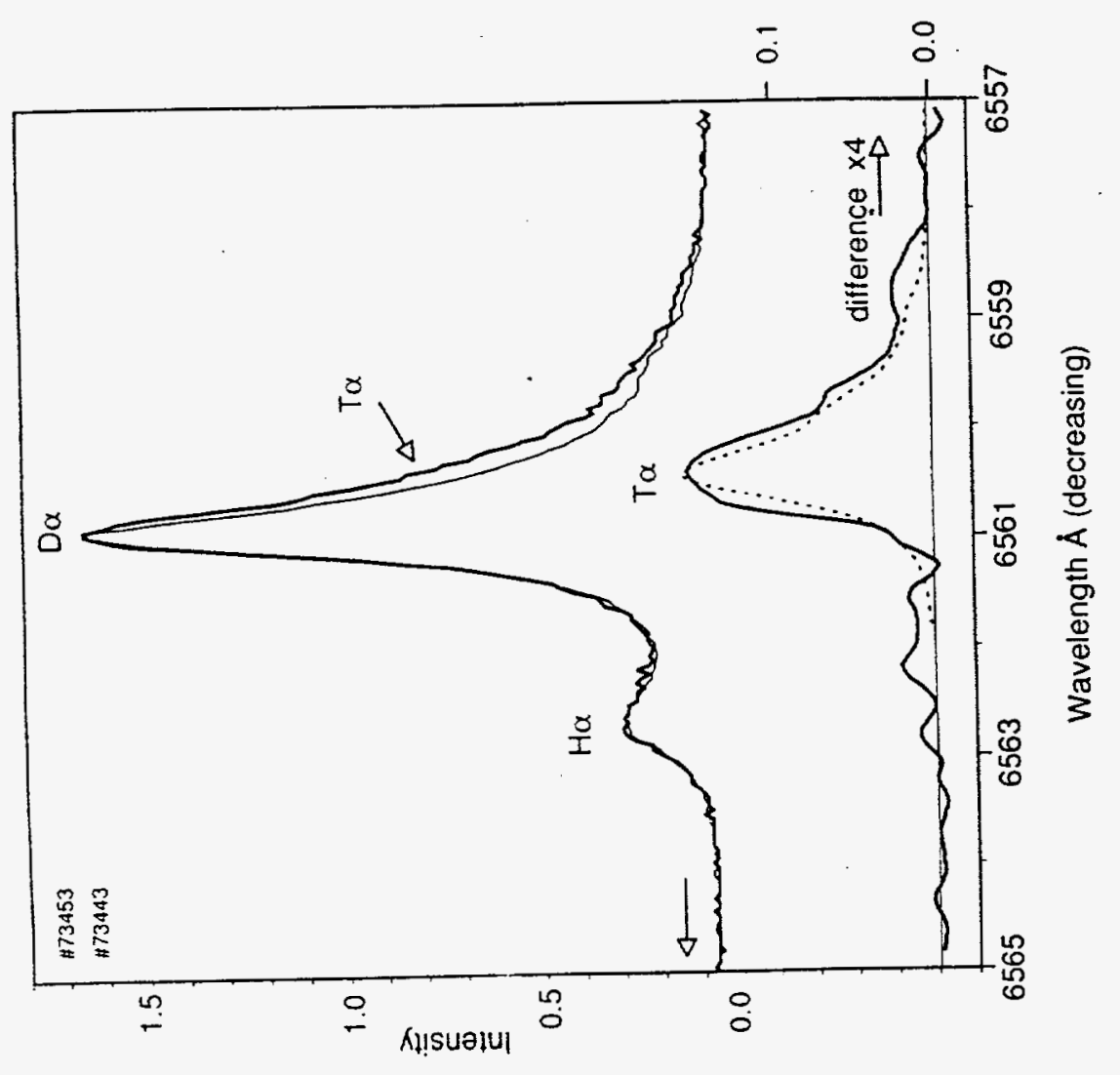

$\dot{0}$

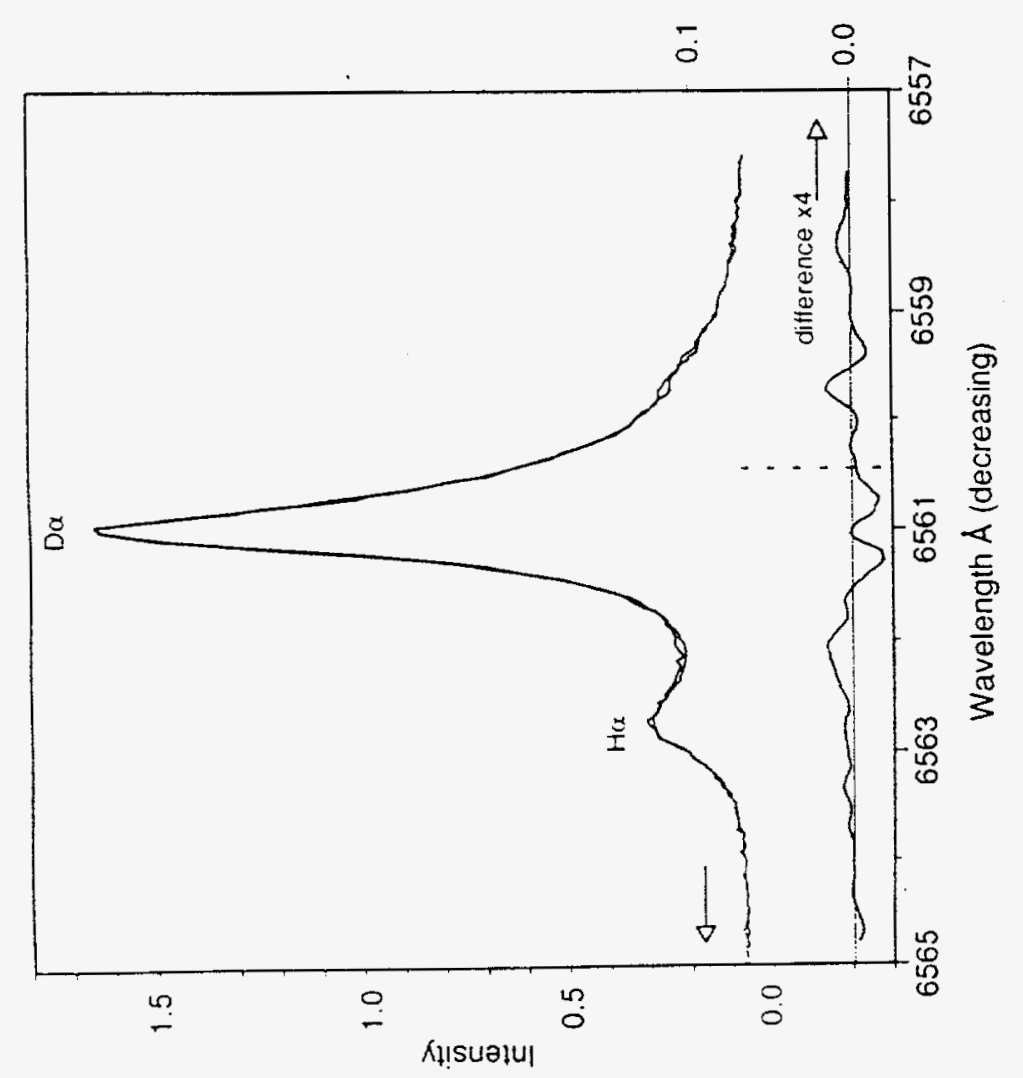

i 
Dr. F. Paoloni, Univ. of Wollongong, AUSTRALIA

Prof. R.C. Cross, Univ. of Sydney, AUSTRALIA

Plasma Research Lab., Australian Nat. Univ., AUSTRALIA

Prof. I.R. Jones, Flinders Univ, AUSTRALIA

Prof. F. Cap, Inst. for Theoretical Physics, AUSTRIA

Prof. M. Heindler, Institut für Theoretische Physik, AUSTRIA

Prof. M. Goossens, Astronomisch Instituut, BELGIUM

Ecole Royale Militaire, Lab. de Phy. Plasmas, BELGIUM

Commission-European, DG. XII-Fusion Prog., BELGIUM

Prof. R. Bouciqué, Rijksuniversiteit Gent, BELGIUM

Dr. P.H. Sakanaka, Instituto Fisica, BRAZIL

Prof. Dr. I.C. Nascimento, Instituto Fisica, Sao Paulo, BRAZIL

Instituto Nacional De Pesquisas Espaciais-INPE, BRAZIL

Documents Office, Atomic Energy of Canada Ltd., CANADA

Ms. M. Morin, CCFWTokamak de Varennes, CANADA

Dr. M.P. Bachynski, MPB Technologies, Inc., CANADA

Dr. H.M. Skarsgard, Univ. of Saskatchewan, CANADA

Prof. J. Teichmann, Univ. of Montreal, CANADA

Prof. S.R. Sreenivasan, Univ. of Calgary, CANADA

Prof. T.W. Johnston, INRS-Energie, CANADA

Dr. R. Bolton, Centre canadien de fusion magnétique, CANADA

Dr. C.R. James, Univ. of Alberta, CANADA

Dr. P. Lukác, Komenského Universzita, CZECHO-SLOVAKIA

The Librarian, Culham Laboratory, ENGLAND

Library, R61, Rutherford Appleton Laboratory, ENGLAND

Mrs. S.A. Hutchinson, JET Library, ENGLAND

Dr. S.C. Sharma, Univ. of South Pacific, FIJI ISLANDS

P. Mähönen, Univ. of Helsinki, FINLAND

Prof. M.N. Bussac, Ecole Polytechnique,, FRANCE

C. Mouttet, Lab. de Physique des Milieux lonisés, FRANCE

J. Radet, CEN/CADARACHE - Bat 506, FRANCE

Prof. E. Economou, Univ. of Crete, GREECE

Ms. C. Rinni, Univ. of loannina, GREECE

Preprint Library, Hungarian Academy of Sci., HUNGARY

Dr. B. DasGupta, Saha Inst. of Nuclear Physics, INDIA

Dr. P. Kaw, Inst. for Plasma Research, INDIA

Dr. P. Rosenau, Israel Inst. of Technology, ISRAEL

Librarian, International Center for Theo Physics, ITALY

Miss C. De Palo, Associazione EURATOM-ENEA , ITALY

Dr. G. Grosso, Istituto di Fisica del Plasma, ITALY

Prof. G. Rostangni, Istituto Gas lonizzati Del Cnr, ITALY
Dr. H. Yamato, Toshiba Res \& Devel Center, JAPAN

Prof. I. Kawakami, Hiroshima Univ., JAPAN

Prof. K. Nishikawa, Hiroshima Univ., JAPAN

Librarian, Naka Fusion Research Establishment, JAERI, JAPAN

Director, Japan Atomic Energy Research inst., JAPAN

Prof. S. Itoh, Kyushu Univ., JAPAN

Research Info. Ctr., National Instit. for Fusion Science, JAPAN

Prof. S. Tanaka, Kyoto Univ., JAPAN

Library, Kyoto Univ., JAPAN

Prot. N. Inoue, Univ. of Tokyo, JAPAN

Secretary, Plasma Section, Electrotechnical Lab., JAPAN

Dr. O. Mitarai, Kumamoto Inst. of Technology, JAPAN

Dr. G.S. Lee, Korea Basic Sci. Ctr., KOREA

J. Hyeon-Sook, Korea Atomic Energy Research Inst., KOREA

D.I. Choi, The Korea Adv. Inst. of Sci. \& Tech., KOREA

Prof. B.S. Liley, Univ. of Waikato, NEW ZEALAND

Inst of Physics, Chinese Acad Sci PEOPLE'S REP. OF CHINA

Library, Inst. of Plasma Physics, PEOPLE'S REP. OF CHINA

Tsinghua Univ. Library, PEOPLE'S REPUBLIC OF CHINA

Z. Li, S.W. Inst Physics, PEOPLE'S REPUBLIC OF CHINA

Prof. J.A.C. Cabral, Instituto Superior Tecnico, PORTUGAL

Prof. M.A. Hellberg, Univ. of Natal, S. AFRICA

Prof. D.E. Kim, Pohang Inst. of Sci. \& Tech., SO. KOREA

Prof. C.I.E.M.A.T, Fusion Division Library, SPAIN

Dr. L. Stenflo, Univ. of UMEA, SWEDEN

Library, Royal Inst. of Technology, SWEDEN

Prof. H. Wilhelmson, Chalmers Univ. of Tech., SWEDEN

Centre Phys. Des Plasmas, Ecole Polytech, SWITZERLAND

Bibliotheek, Inst. Voor Plasma-Fysica, THE NETHERLANDS

Asst. Prof. Dr. S. Cakir, Middle East Tech. Univ., TURKEY

Dr. V.A. Glukhikh,Sci. Res. Inst. Electrophys.I Apparatus, USSR

Dr. D.D. Ryutov, Siberian Branch of Academy of Sci., USSR

Dr. G.A. Eliseev, I.V. Kurchatov Inst., USSA

Librarian, The Ukr.SSR Academy of Sciences, USSR

Dr. L.M. Kovrizhnykh, Inst. of General Physics, USSR

Kernforschungsanlage $\mathrm{GmbH}$, Zentralbibliothek, W. GERMANY

Bibliothek, Inst. Für Plasmaforschung, W. GERMANY

Prof. K. Schindler, Ruhr-Universitát Bochum, W. GERMANY

Dr. F. Wagner, (ASDEX), Max-Planck-Institut, W. GERMANY

Librarian, Max-Planck-Institut, W. GERMANY 